\title{
Erratum to: Safety and Tolerability of Gabapentin for Aneurysmal Subarachnoid Hemorrhage (SAH) Headache and Meningismus
}

Laxmi P. Dhakal · David O. Hodge •

Jay Nagel $\cdot$ Michael Mayes $\cdot$ Alexa Richie $\cdot$

Lauren K. Ng • William D. Freeman

Published online: 9 December 2014

(C) Springer Science+Business Media New York 2014

\section{Erratum to: Neurocrit Care}

\section{DOI 10.1007/s12028-014-0086-5}

In the published article, the spelling of the author Jay Nagal's last name was incorrect and is now corrected in this erratum. The authors apologize for this error.

The online version of the original article can be found under doi:10. 1007/s12028-014-0086-5.

L. P. Dhakal · L. K. Ng

Department of Critical Care, Mayo Clinic, Jacksonville, FL,

USA

D. O. Hodge

Department of Health Sciences Research, Mayo Clinic,

Jacksonville, FL, USA

J. Nagel

Department of Emergency Medicine, Mayo Clinic, Jacksonville,

FL, USA

M. Mayes

Department of Pharmacy, Mayo Clinic, Jacksonville, FL, USA

\section{A. Richie}

Clinical Study Unit, Department of Neurology, Mayo Clinic,

Jacksonville, FL, USA

W. D. Freeman $(\square)$

Departments of Neurology Neurosurgery and Critical Care,

Mayo Clinic, 4500 San Pablo Road, Jacksonville, FL 32224,

USA

e-mail: freeman.william1@mayo.edu 